\title{
Comparing Dung Beetle Species Assemblages Between Protected Areas and Adjacent Pasturelands in a Mediterranean Savanna Landscape
}

\author{
Catherine Numa, ${ }^{1}$ José R. Verdú, ${ }^{2}$ Cristina Rueda, ${ }^{3}$ and Eduardo Galante ${ }^{2}$
}

Authors are ${ }^{1}$ Postdoctoral fellow and ${ }^{2}$ Professor, Centro Iberoamericano de la Biodiversidad (CIBIO), Universidad de Alicante, San Vicente del Raspeig, 03080 Alicante, Spain; and ${ }^{3}$ Professor, Universidad Nacional de Jujuy, Facultad de Ciencias Agrarias, San Salvador de Jujuy, CP 4600, Argentina.

\begin{abstract}
Dung beetles are considered keystone species because of their role in decomposition, seed dispersal, and control of vertebrate parasites in grazed habitats. Despite the ecological importance of this group to pasture ecosystem functioning, still little is known about its relationship with grazing management activities. We evaluated the conservation value of protected areas for dung beetle diversity by comparing two different management conditions of Mediterranean savanna in central Spain. Four different sites with wild herbivory (red deer, roe deer) were sampled inside the Cabañeros National Park, and four sites with traditional agrosilvopastoral management were sampled in a sheep farm near the park. The dung beetle species richness was similar between savanna conditions, but the total dung beetle abundance and biomass were considerably greater in the park grasslands than in the grasslands of the sheep farm. Dung beetle species composition, species dominance, and abundance by functional groups from both park and farm sites were different, despite the high similarity among the sampled sites in both hydric content and dung availability. Onthophagus maki (Illiger 1803) and O. furcatus (Fabricius 1781) were the dominant species in the park, while O. furcatus, Aphodius foetidus (Herbst 1783), and Caccobius schreberi L. were the dominant species on the farm. Species richness and abundance of telecoprids were higher in the park than on the farm. Abundance of paracoprids was also higher in the park than on the farm, while no differences in species richness and abundance of endocoprids were observed between both conditions. These results suggest that management activities such as plowing and the use of veterinary substances affect soil structure and dung quality and could be important factors that alter dung beetle assemblages in terms of composition, abundance, and biomass on traditional farms.
\end{abstract}

\section{Resumen}

Los escarabajos coprófagos se consideran especies clave debido a su papel en la descomposición, dispersión de semillas y control de parásitos de vertebrados en los hábitats con pastoreo. A pesar de la importancia ecológica de este grupo para el funcionamiento de los ecosistemas de pastizal, aun se conoce poco acerca de su relación con el manejo del pastoreo. Evaluamos el valor de conservación de las áreas protegidas para la diversidad de escarabajos coprófagos, comparando dos tipos de manejo de la herbivoría en pastizales mediterráneos de España central. Se muestrearon cuatro sitios con alta herbivoría de ciervo y corzo dentro del Parque Nacional de Cabañeros y cuatro sitios en una granja de ovejas con manejo agrosilvopastoral tradicional cerca del parque. La riqueza de especies de escarabajos coprófagos en las dos condiciones de manejo fue similar pero la abundancia y la biomasa fueron considerablemente mayor es en los pastizales del parque, que en los pastizales de la granja de ovejas. A pesar de la alta similitud entre los sitios muestreados en cuanto a disponibilidad y contenido hídrico del excremento, la composición, dominancia y grupos funcionales de especies fueron diferentes entre las dos condiciones de manejo. Onthophagus maki (Illiger 1803) y O. furcatus (Fabricius 1781) fueron las especies dominantes en el parque, mientras que O. furcatus, Aphodius foetidus (Herbst 1783) y Caccobius schreberi L. fueron las especies dominantes en la granja. La riqueza y abundancia de telecópridos fueron mayores en el parque que en la finca. La abundancia de paracópridos fue también mayor en el parque. Pero no se observaron diferencias en la riqueza y abundancia de endocópridos entre las dos condiciones de manejo. Estos resultados sugieren que algunas actividades del manejo de pastizales como la labranza y el uso de sustancias de uso veterinario que afectan la estructura del suelo y la calidad del excremento podrían ser factores importantes que alteran los ensambles de escarabajos coprófagos en términos de diversidad, abundancia y biomasa en las granjas de manejo tradicional.

Key Words: land use, livestock management, natural protected areas, Scarabaeoidea, species diversity

\section{INTRODUCTION}

The research was funded by the projects 040/2002 of the Ministerio de Medio Ambiente, Medio Rural y Marino of Spain, GV05/096 of the Consellería de Empresa Universidad y Ciencia Generalitat Valenciana, and CGL2005/07213/BOS, CGL2008/03878/BOS of the Ministerio de Educación, Ciencia e Innovación.

Correspondence: Catherine Numa, Centro Iberoamericano de la Biodiversidad (CIBIO), Universidad de Alicante, San Vicente del Raspeig, 03080 Alicante, Spain. Email: numa@ua.es

Manuscript received 29 March 2010; manuscript accepted 21 November 2011.
Mediterranean landscapes are characterized by a high level of heterogeneity, as a result of climatic and topographic variability and human influence (Blondel and Aronson 1999). The long history of adaptation of human activities to environmental conditions in the Mediterranean region has been associated with high levels of biodiversity (Naveh and Whittaker 1979). Livestock and wild herbivory are the main activities that have maintained a vegetation structure consisting of grasslands 
within forest and scrubland mosaics (Debussche et al. 1999; Svenning 2002). Linked to the herbivory of large mammals, a large proportion of dung beetle fauna in the Mediterranean region inhabits pasturelands (Lumaret and Kirk 1991; Lobo and Davis 1999).

Dung beetles are important organisms that are involved in many ecosystem processes, such as nutrient recycling (Bang et al. 2005), seed dispersal (Andresen and Levey 2004), and control of pest flies and parasites of vertebrates (Horgan 2005). Based on their food relocation behavior (Halffter and Matthews 1966; Bornemissza 1969, 1976; Doube 1990), dung beetles have generally been divided into three functional groups: paracoprids, which dig tunnels and construct their nests directly under the dung mass; endocoprids, which create a nest chamber within the dung; and telecoprids, which detach a portion of dung from the mass, roll it some distance away from the source, and then bury it. Under this functional diversity, many factors can influence dung beetle presence and abundance. Vegetation structure, soil type, and habitat quality can influence the species occurrence and abundance in function of certain species traits such as mouthpart adaptations (Verdú and Galante 2004) and thermoregulatory traits (Verdú and Lobo 2008). The hydric content of dung and dung density can also influence the diversity and abundance patterns of many species (Lumaret et al. 1992; Lobo et al. 2006). Some species prefer dung types with high hydric content, such as cow feces, whereas others have morphological adaptations for consuming feces with low hydric content and are more frequently found in pellets of sheep, deer, or rabbit (Verdú and Galante 2004). In addition, the characteristics of the microhabitats might differentially influence the nesting success of functional groups. Paracoprids, which do not have dung reallocation behavior, such as telecoprids, might be more sensitive to the alteration of the soil characteristics under dung pats (Sowig 1995). In a similar manner, endocoprids might be more affected than other functional groups when dung is exposed to high temperatures and low moisture, as is the case in open areas, where dung dries out quickly, lowering its nutrient quality.

Recent changes in land use and farming practices seem to have had consequences on dung beetle abundance and presence, frequently causing local extinctions of some dung beetles species, mainly rollers (Lobo 2001; Carpaneto et al. 2007). For example, farming abandonment has reduced the grazing areas in the Mediterranean region (European Environment Agency 2005) and has therefore affected the spatial availability of feces and the distribution patterns of both dung beetle species richness and biomass (Lobo et al. 2006; Jay-Robert et al. 2008). In addition, the intensification of agriculture and grazing management, including the use of chemical substances (e.g., insecticides for cultures) and the frequent use of veterinary drugs for cattle, is detrimental to dung beetle populations (Lumaret et al. 1993) and might influence dung beetle biodiversity patterns (Hutton and Giller 2003).

Long-term (10000-8000 BC) presence of humans in the Mediterranean region has increased landscape heterogeneity and therefore the gamma biodiversity of organisms. Protected areas, where human activities are excluded, play a crucial role in alpha biodiversity conservation by providing high-quality resources, maintenance of habitat conditions, etc. There is evidence that protected areas, where wild herbivores (red deer and roe deer mainly) and/or domestic herbivores (sheep, goats and cows, mainly) graze, maintain heterogeneous vegetation mosaics and high species richness and abundances of dung beetles (Verdú et al. 2007; Numa et al. 2009). However, some traditional farming activities (e.g., transhumance livestock) have been eliminated in many natural reserves and protected areas of the Iberian Peninsula due to management practices normally based on the protection of forest to the detriment of scrubland and grassland conservation (Villar and Montserrat 1995). This management procedure seems to have a negative impact on the invertebrate fauna and flora if the grazing activity level is not immediately supplied with the reintroduction of wild herbivores and/or the return of transhumance livestock production (Verdú et al. 2000).

Thus, to elucidate the effects of different grazing types on biodiversity, we examined the value of a particular protected area for the conservation of dung beetle biodiversity by comparing dung beetle assemblages in the Cabañeros National Park (a Mediterranean oak savanna ecosystem), characterized by high wild grazing activity (by red deer, mainly) and in an adjacent agrosilvopastoral farm that has the same vegetation type but different management methods and extensive sheep grazing. We hypothesized that in similar conditions of vegetation type and dung resource availability, farming practices (e.g., soil plowing, application of chemical substances) affect dung beetle assemblages in agrosilvopastoral savanna resulting in changes in abundance, biomass, species richness, and species composition of the dung beetle assemblages when compared to protected savanna.

\section{METHODS}

\section{Study Area}

The study area comprises the savanna of Cabañeros National Park and adjacent savanna areas outside the park. This area is located at the center of the Iberian Peninsula (lat $39^{\circ} 24^{\prime} \mathrm{N}$, long $0^{\circ} 35^{\prime} \mathrm{W}$ ), $638 \mathrm{~m}$ a.s.l. of altitude and is in the Mediterranean region with a moderate Mediterranean climate, a dry summer period, and annual rainfall between $500 \mathrm{~mm}$ and $750 \mathrm{~mm}$ and annual temperature variation between $18^{\circ} \mathrm{C}$ and $21^{\circ} \mathrm{C}$ with a maximum temperature of $40^{\circ} \mathrm{C}$ and minimum temperatures of $-12^{\circ} \mathrm{C}$.

Land uses in the study area have not experienced major changes in the last $20 \mathrm{yr}$ (Vaquero de la Cruz 1997). The park comprises 40856 ha, with a continuous savanna vegetation area of around 6300 ha. This park was declared a protected area in 1983 (http://reddeparquesnacionales.mma.es/en/parques/ cabaneros/home_parque_cabaneros.htm). Before this declaration, the zone was a hunting reserve, although some areas of grassland were devoted to agriculture and livestock. The savanna vegetation includes open pastures mainly composed of Avena barbata Pott ex Link (comprising around $80-90 \%$ of cover), Echium plantagineum L., and Holcus setiglumis Boiss and Reuter and has scattered trees of Quercus ilex spp. ballota (Desf.) Samp., Quercus suber L. (tree density: $4.7 \pm 2.3$ trees $\cdot \mathrm{ha}^{-1}$ ), and Quercus faginea Lam. The National Park has wild herbivores, including abundant red deer (Cervus elaphus L.) and roe deer (Capreolus capreolus L.) populations.

The other savanna sites selected were located $4.5 \mathrm{~km}$ outside the park on the "Las Póvedas" farm. This is a 1000 ha 
traditional sheep farm with the same soil type, vegetation structure, and tree species as the savanna within the park (tree density: $7.8 \pm 1.3$ trees $\cdot \mathrm{ha}^{-1}$ ); however, the farm has a 3 -yr rotational plowing system with cereal culture of $A$. barbata, grass growth, and sheep grazing. The farm has been devoted to sheep livestock for more than $30 \mathrm{yr}$.

The density of herbivores, and therefore the quantity of dung at the two sites, was not a limited resource in either area. This was corroborated by observation of several remaining pellets of different ages during the activity period of dung beetles. Additionally, measurements of dung density in the park showed no differences between habitat types (Numa et al. 2009, supplementary material). The deer and roe deer populations in the studied zone of the park were estimated at 2188 individuals (0.3 individuals $\cdot \mathrm{ha}^{-1}$ in the savanna sector). Sheep livestock production of Las Póvedas farm was $1.5 \mathrm{sheep} \cdot \mathrm{ha}^{-1}$ at the time of the study. Sheep and deer dung are similar in odor, form, and hydric content; therefore, potential differences in dung beetle assemblage between protected and managed areas should be expected due to factors related to land management practices such as soil alteration, chemical inputs, or changes in the quality of dung.

Even though there are differences between deer and sheep grazing behaviors (Piasentier et al. 2007), it seems that there were no consistent differences in pasture consumption and pasture species selection between deer and sheep (Hester et al. 1996; Trotter et al. 2006). Similarly, vegetation structure was the same in both grazing systems analyzed.

\section{Dung Beetle Sampling}

We selected four sampling sites at each of the two localities. Dung beetles were sampled using standardized methodology (Verdú et al. 2000) using three pitfall traps at each sampling site, with at least $50 \mathrm{~m}$ between the traps and at least $600 \mathrm{~m}$ between the sampling sites. A total of 12 pitfall traps were installed randomly in each locality. Traps were baited with sheep dung because this type of dung is similar in form, odor, and composition to the deer dung available within the park (Numa et al. 2009). In both localities we used the same type of dung in order to attract the same assemblage of species and have a better idea of the influence of the management type on the species' presence and abundance. To minimize possible effects of veterinary substances in dung, pellets were recollected at the end of winter before the beginning of any veterinary treatment. Dung was frozen until the sampling period. The sampling was carried out over two periods of $7 \mathrm{~d}$ in May 2005, which is the month with the most dung beetle activity in this region (Numa 2008).

\section{Diversity Analysis}

All of the dung beetles captured were identified to species level. Estimates of expected species richness and comparisons of these predictions between park and farm savanna study sites were calculated using two nonparametric richness estimators: one incidence-based and one abundance-based (ICE and ACE) using EstimateS 8.2 (Colwell 2005). The ICE estimator is based on species found in fewer than 11 sampling units (Lee and Chao 1994), whereas the ACE estimator is based on those species with fewer than 11 individuals in the sample (Chao et al. 1993).
The inventory completeness at each savanna type was measured as the percentage of species observed from the total number of species predicted by estimators. We tested for differences in the mean alpha diversity (species richness per sampling site, $N=4$ ) and the abundance of individuals (total individuals per sampling site, $N=4$ ) among farm and park sites using Mann-Whitney tests (StatsDirect 2008). The relationship between management conditions and total abundance (individuals per study site) and total biomass (total weight per study site) were also examined.

\section{Dung Beetle Abundance and Biomass}

To analyze species-abundance patterns among management conditions, we constructed rank-abundance plots. These graphs are a useful tool to explore attributes of the assemblage, such as species richness (number of points), evenness (slope), number of rare species (tail of the curve), and relative abundance of each species (order of the species in the graph). We tested differences in slope between both curves through a nonparametric analysis of covariance, with a null hypothesis of parallelism, using the sm package in R. The nonparametric ANCOVA test allows a set of nonparametric regression curves to be compared, and the reference models, used to define the null hypothesis, may be of either equality or parallelism (see Young and Bowman 1995).

We also graphically examined the relationship between the species biomass and abundance in each type of savanna according to the functional groups of dung beetles (see below). The biomass was estimated for each species using the regression formula Biomass $=0.010864 \times$ Length $^{3.316}$, which was proposed for Iberian dung beetles (Lobo 1993) and is based on the mean species body length.

Differences in species composition between management conditions were measured with the Bray-Curtis dissimilarity index (Magurran 2004). The abundance data were square root transformed before analysis. To compare the species composition between both management conditions, an ANOSIM analysis (Clarke and Warwick 1994) was performed using PRIMER software (Clarke and Gorley 2001). Nonmetric multidimensional scaling (MDS) was used to examine the dissimilarity between the samples. MDS places sample plots into the ordination space in such a manner that the ordination distances correspond to differences in species composition and abundances.

\section{Functional Groups Analysis}

Based on the presence of different functional groups of dung beetles (Halffter and Matthews 1966), we analyzed species richness and abundance in relation to habitat use. Three categories were considered for our analysis: endocoprids, paracoprids, and telecoprids. We compared the functional group species richness and abundance between management conditions using Mann-Whitney tests (StatsDirect 2008).

\section{RESULTS}

\section{Diversity Analysis}

In total 9225 individuals belonging to 37 dung beetle species were collected. Our inventories had more than $90 \%$ of completeness at each locality, and over the entire study, we 


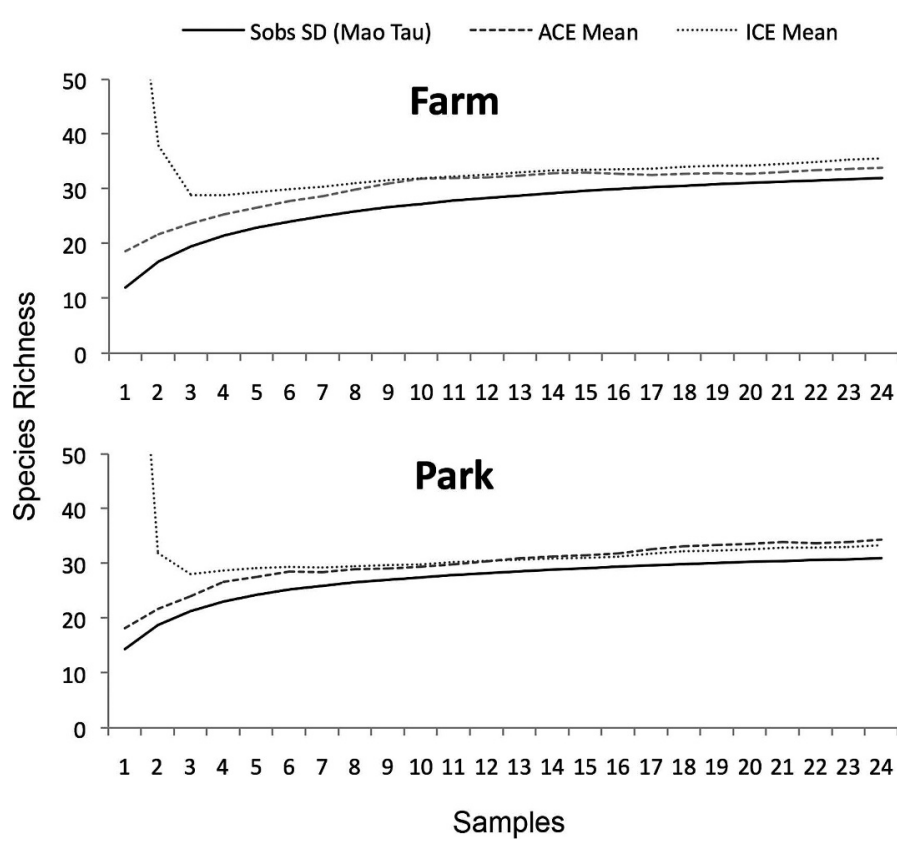

Figure 1. Observed species richness (Sobs Mao Tau), ICE, and ACE estimators as a function of the sampling effort (pitfall traps) for dung beetles at savannas in Cabañeros National Park and Las Póvedas farm.

recorded $92 \%$ of the expected species richness according to the ACE and ICE estimators (Fig. 1).

The cumulative alpha species diversity was similar for both savanna types; 31 and 32 species were observed in the National Park and farm area, respectively. The species richness within each sampling site did not show differences between park and farm (Mann-Whitney test: $U=5, P<0.37$ ) (Fig. 2), but the dung beetle abundance (Fig. 2) and biomass were greater at the park sites than at the farm sites (Mann-Whitney test: abundance, $U=0, P<0.02$; biomass, $U=0, P<0.02)$. The differences between both areas could also be observed in the total and mean values of abundance and biomass. The total abundance was more than five times higher in the park than on the farm (park $=7792$ individuals; farm $=1493$ individuals). Similarly, total biomass in the park was $96.1 \mathrm{~g}$, whereas it was $18.3 \mathrm{~g}$ on the farm. Similar differences were observed in the mean abundance and biomass [Abundance (individuals): farm $\bar{x}=358.25 \pm 134.2 ;$ park $\bar{x}=1948 \pm 249.9$. Biomass (in g): farm $\bar{x}=4.5 \pm 1.1 ;$ park $\bar{x}=23.8 \pm 2.8]$.

The species-rank plots of the farm and park sites was statistically different according to the parallelism test (RANKANCOVA: $h=2.48 ; P=0.001)$. The species-rank plots were similar in slope, although an increase in evenness and the proportion of apparently rarer species was observed on the farm sites (Fig. 3). In the park an evident dominance of two paracoprids, Onthophagus maki (Illiger 1803) and Onthophagus furcatus (Fabricius 1781), was observed (61\% of the total abundance). In contrast, the farm showed a dominance of Onthopahus furcatus (paracoprid), Aphodius foetidus (Herbst 1783) (endocoprid), and Caccobius schreberi L. (paracoprid), which comprised $57 \%$ of the total abundance.

Large differences in dung beetle species composition were observed between the farm and park sampling sites (ANOSIM; $R=1, P<0.0001)$. As can be observed in the MDS, the

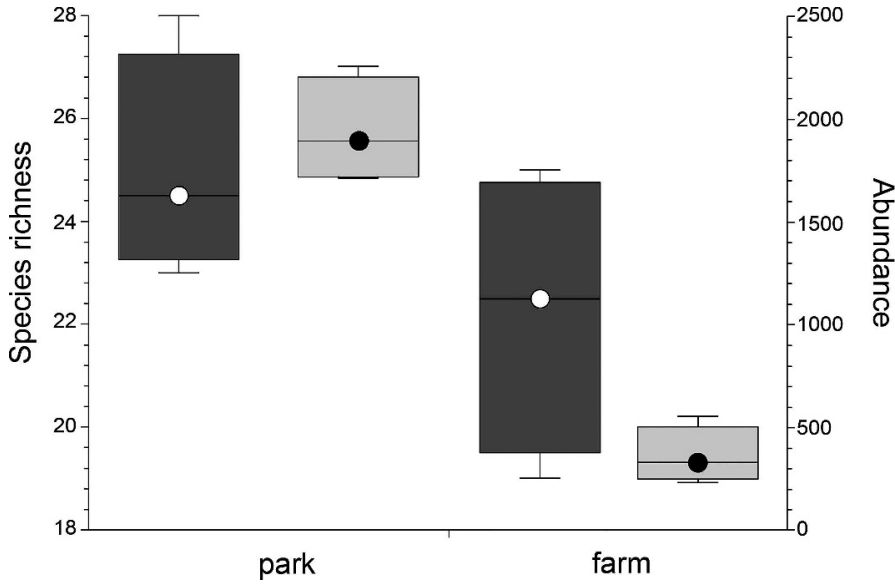

Figure 2. Median of species richness (white circles) and abundance (black circles) of dung beetles at savannas in Cabañeros National Park and Las Póvedas farm. Bars represent maximum and minimum values.

sampling sites are split into two clear groups of dung beetle species according to the management conditions (Fig. 4).

\section{Functional Groups}

The influence of the type of management in the savannas on the species richness and abundance of functional groups was also observed (Fig. 5). The species richness and abundance of telecoprid dung beetles was greater at the park site (MannWhitney tests: species richness, $U=0.5, P<0.05$; abundance, $U<0.01, P<0.05)$; the species richness of paracoprids was similar between land use conditions, but paracoprid abundance was greater in the park (Mann-Whitney tests: species richness, $U=6, P<0.49$; abundance, $U<0.01, P<0.05$ ); endocoprids were similar in species richness and abundance between both land use conditions (Mann-Whitney tests: species richness, $U=4, P<0.2$; abundance, $U=2 ; P<0.08)$.

\section{DISCUSSION}

Our results show that both pasturelands with high herbivory activity but different grazing management differ in their dung beetle assemblages. Although the species richness did not vary among grazing systems, the main differences were observed in both the species composition and abundance. These results show a similar pattern to dung beetle assemblages in the northern Mediterranean, where species richness of dung beetles was also similar between sheep and deer grazed pastures; however, in that case, there was no difference in dung beetle abundance between pastures (supplementary material in JayRobert et al. 2008). In the same region, changes in dung beetle abundance and biomass were observed when sheep grazing was changed to cattle grazing. Five years after the change of grazing type, the species richness did not vary significantly, but the density of dung resources increased, and drastic changes in total biomass and relative abundance of species were observed (Lumaret et al. 1992).

In our study area, where both park and farm places had similar dung availability and where the characteristics of the available feces were practically similar (e.g., composition, size, 


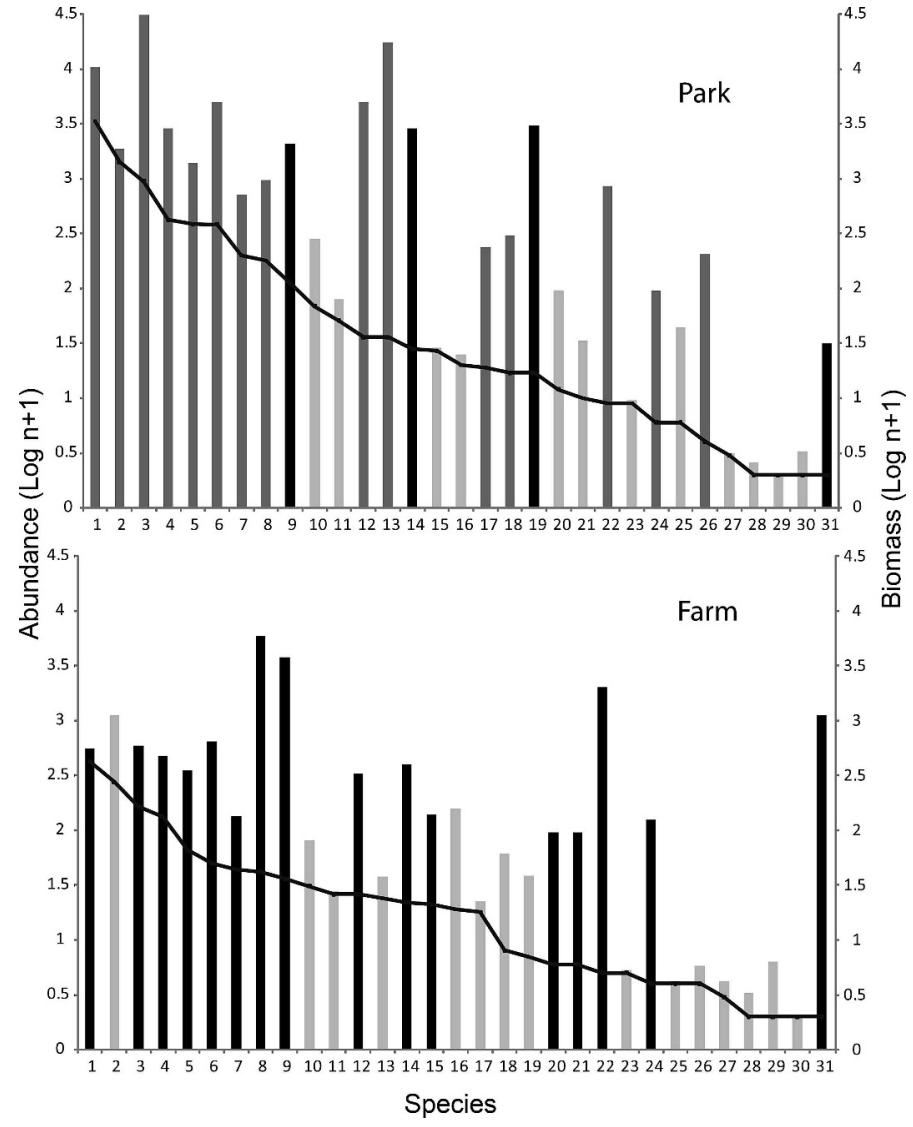

Figure 3. Rank-abundance (line) and total-biomass (bars) plots of dung beetles assemblages at Cabañeros National Park and a nearby sheep farm. Light bars correspond to endocoprid species, dark gray bars are paracoprid species, and black bars are telecoprid species.

and hydric content), dung beetle assemblages seemed to be strongly influenced by the management of grazing. Compared to the park, the main effects observed in the sheep farm were a decrease in dung beetle abundance and biomass, a reduction of both telecoprid species richness and paracoprid abundance, and an increase in the abundance of the endocoprid and generalist species A. foetidus. Similar results have been observed in grazing farms with different levels of intensification. For example, in southern Ireland, dung beetle abundance and biomass were lower in farms with intensive management (where grass fertilizers and anthelmintics for livestock are used) than in organic farms (where these substances are not applied); in the intensively managed farm, Aphodius species composed more than $90 \%$ of individuals observed (Hutton and Giller 2003).

The abundance and biomass of beetles in grazing systems is one measure of dung disposal. Pat degradation and nutrients recycling are the most important ecological roles of dung beetles. Without such recycling, pastures become covered by patches of grass with lower digestibility and nutritive value, eventually becoming unsuitable for grazing (Gittings et al. 1994). Our observations of a strong decrease of dung beetle abundance and biomass in the grazing farm emphasize the need to evaluate the influence of different management activities on the dung beetle assemblages.

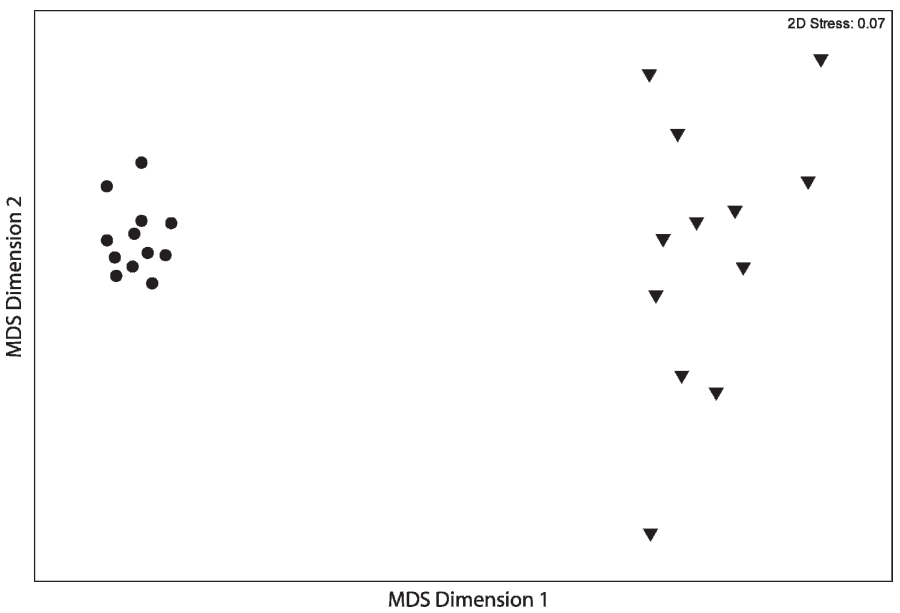

Figure 4. MDS showing the species composition of dung beetles recorded in savanna sites with different types of management. Circles correspond to Cabañeros National Park, and triangles correspond to the neighboring farm sites.

One farming activity that needs more investigation is the use of veterinary medicinal products to control endoparasites in farm livestock (e.g., avermectins, pyrethroids, and other substances) (Lumaret and Eroussi 2002; Hutton and Giller 2003). Some of these substances are excreted in the dung after 12 wk of treatment, which leads to dung-inhabiting invertebrates being exposed to toxic effects (Lumaret et al. 1993). The dung of animals treated with these anthelmintics produces high larval mortality of dung beetles (Lumaret and Martínez 2005), which could lead to a reduction of $25-35 \%$ of the next generation population in some species (Wardhaugh et al. 2001). On the farmland studied, sheep received anthelmintic treatment with benzimidazole derivatives. This treatment could be an important factor to explain the differences between the grazing systems, but the effects of other internal anti-parasite substances different from the ones cited above are still unknown.

Additionally, functional groups of dung beetles have different habitat requirements for larval development: Telecoprids and paracoprids require determinate soil characteristics for burying dung and building nests (Bertone et al. 2006), whereas embryogenic development of endocoprids occurs in the dung pat and the soil interface (Halffter and Matthews 1966). Grazing management entails, on occasion, trampling, overgrazing, and activities such as plowing, which affect soil structure. The farm studied had been plowed 6 mo before the sampling. This plowing might have influenced the microhabitats of telecoprids and especially nesting paracoprids, which do not have dung reallocation behavior such as telecoprids. In general, larger dung beetle species and/or telecoprids are more severely affected by plowing than smaller and/or endocoprid dung beetle species (Jankielsohn 2001). The same occurs in intensive farms, where the abundance of large dung beetles (e.g., geotrupids) is lower than in organic farms (Hutton and Giller 2003). In this sense, large dung beetles might be more sensitive to factors such as dung availability (Nichols et al. 2007) or soil compaction (Navarrete and Halffter 2008). Furthermore, large dung beetles generally have both longer larval cycles and lower rates of egg laying than the smaller ones (Verdú 1998). All these factors may increase the probability 

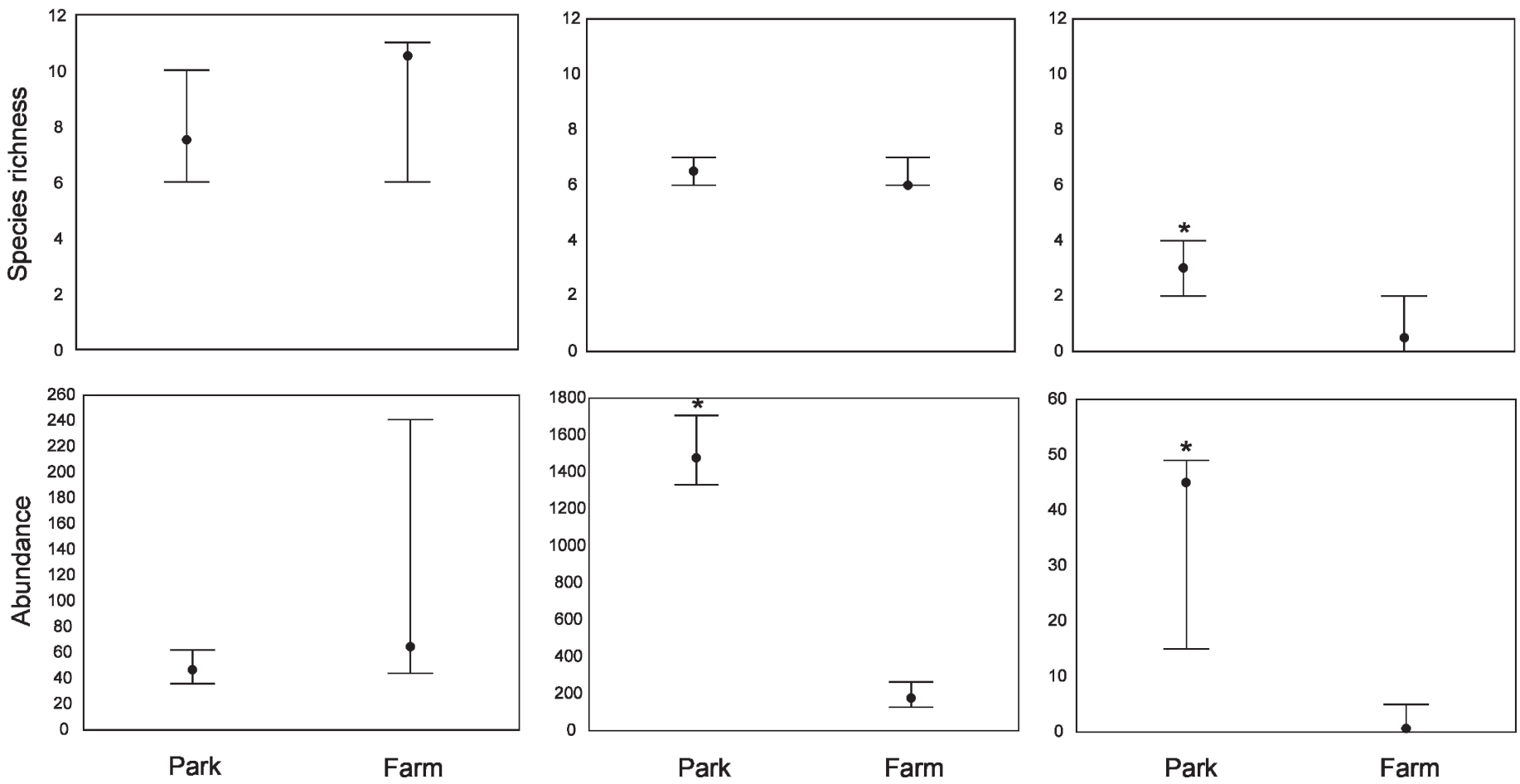

Figure 5. Species richness and abundance of functional groups of dung beetles on the farm and park sites. Bars represent maximum and minimum, and dots represent the median values. Significant differences between sites (Mann-Whitney $U ; P<0.05$ ) are marked with an asterisk.

that management activities affect microhabitats and individual survival in large dung beetles.

Our results emphasize the importance of grazing activities and the need for adequate livestock management on pastureland ecosystems to maintain the ecological process of recycling feces by a well-preserved dung beetle community (Verdú et al. 2000). Regional changes in land use due to urbanization, pasture abandonment, and agricultural intensification have reduced the number of favorable habitat areas for dung beetles (Lobo 2001; Nichols et al. 2007). In the actual scenario, traditional grazing systems have been considered to be important for maintaining dung beetle diversity (Verdú et al. 2000) because they maintain heterogeneous vegetation and open habitats and their feces provide food resources for dung beetles (Verdú et al. 2000; JayRobert et al. 2008). However, traditional management can also entail activities with detrimental effects on dung beetle populations. More research about the effects of farming management (trampling, plowing, fertilization, pesticides, veterinary products) on Mediterranean oak savanna biodiversity is necessary to adopt more effective policies to stop the general biodiversity decline in agricultural landscapes (Kleijn and Sutherland 2003).

\section{IMPLICATIONS}

Two important aspects for the conservation of dung beetle diversity emerge from this work: the crucial role of grazed protected areas in maintaining larger dung beetle populations and greater biomass, and the effects of livestock management on dung beetle assemblages. Traditional grazing systems are generally associated with low levels of herbivory and extensive management of livestock, but knowledge of how certain practices, such as plowing and using chemical inputs, affect the quality of dung and soil, species assemblages, and ecosystem functioning is essential to formulate effective measures of biodiversity conservation in grazing systems.

\section{ACKNOWLEDGMENTS}

We would like to thank the staff of Cabañeros National Park, especially José Jiménez and Ángel Gómez, for providing landscape data and logistic facilities for the fieldwork. We would also like to thank Daniel Salgado of Las Póvedas farm for allowing us to carry out the sampling.

\section{LITERATURE CITED}

Andresen, E., and D. J. Levey. 2004. Effects of dung and seed size on secondary dispersal, seed predation, and seedling establishment of rainforest trees. Oecologia 139:45-54.

Bang, H. S., J.-H. Lee, O. S. Kwon, Y. E. Na, Y. S. Jang, and W. H. Kim. 2005. Effects of paracoprid dung beetles (Coleoptera: Scarabaeidae) on the growth of pasture herbage and on the underlying soil. Applied Soil Ecology 29:165-171.

Bertone, M. A., J. T. Green, S. P. Washburn, M. H. Poore, and D. W. Watson. 2006. The contribution of tunneling dung beetles to pasture soil nutrition. Forage and Grazinglands. doi:10.1094/FG-2006-0711-02-RS

BLONDEL, J., AND J. ARonson. 1999. Biology and wildlife of the Mediterranean region. Oxford, UK: Oxford University Press. $328 \mathrm{p}$.

Bornemissza, G. F. 1969. A new type of brood care observed in the dung beetle Oniticellus cinctus (Scarabaeidae). Pedobiologia 9:223-225.

Bornemissza, G. F. 1976. The Australian dung beetle project 1965-1975. Australian Meat Research Committee Review 30:1-32.

Carpaneto, G. M., A. Mazziotta, and L. Valerio. 2007. Inferring species decline from collection records: roller dung beetles in Italy (Coleoptera, Scarabaeidae). Diversity and Distributions 13:903-919. 
Chao, A., M.-C. Ma, and M. C. K. Yang. 1993. Stopping rules and estimation for recapture debugging with unequal failure rates. Biometrika 80:193-201.

Clarke, K., and R. M. Warwick. 1994. Similarity-based testing for community pattern: the 2-way layout with no replication. Marine Biology 118:167-176.

Clarke, K. R., and R. M. Warwick. 2001. Change in marine communities: an approach to statistical analysis and interpretation. 5th ed. Plymouth, UK: Primer-E Ltd. $172 \mathrm{p}$.

Colwell, R. K. 2005. EstimateS: statistical estimation of species richness and shared species from samples. Version 8.0. User's guide and application. Available at: http://purl.oclc.org/estimates. Accessed 9 September 2010.

Debussche, M., J. Lepart, and A. Dervieux. 1999. Mediterranean landscape changes: evidence from old postcards. Global Ecology and Biogeography 8:3-15.

DouBE, B. M. 1990. A functional classification for analysis of the structure of dung beetle assemblages. Ecological Entomology 15:371-383.

European Environment Agency. 2005. The European environment-state and outlook 2005, Copenhagen. Available at: http://www.eea.europa.eu/publications/state_ of_environment_report_2005_1. Accessed 30 July 2010.

Gittings, T., P. S. Giller, and G. Stakelum. 1994. Dung decomposition in contrasting temperate pastures in relation to dung beetle and earthworm activity. Pedobiologia 38:455-474.

Halffter, G., and E. G. Matthews. 1966. The natural history of dung beetles of the subfamily Scarabaeinae (Coleoptera, Scarabaeidae). Folia Entomológica Mexicana 12-14:1-312.

Hester, A. J., F. J. G. Mitchell, I. J. Gordon, and G. J. Baillie. 1996. Activity patterns and resource use by sheep and red deer grazing across a grass/heather boundary. Journal of Zoology 240:609-620.

Horgan, F. G. 2005. Effects of deforestation on diversity, biomass and function of dung beetles on the eastern slopes of the Peruvian Andes. Forest Ecology and Management 216:117-133.

Hutton, S., AND P. S. Giller. 2003. The effects of the intensification of agriculture on northern temperate dung beetle communities. Journal of Applied Ecology 40:994-1007.

JankIELSOHn, A., C. H. Scholtz, ANd S. V. Louw. 2001. Effect of habitat transformation on dung beetle assemblages: a comparison between a South African nature reserve and neighboring farms. Environmental Entomology 30:474-483.

Jay-Robert, P., J. Niogret, F. Errouissi, M. Labarussias, É. Paoletti, M. V. Luis, and J.-P. LumARET. 2008. Relative efficiency of extensive grazing vs. wild ungulates management for dung beetle conservation in a heterogeneous landscape from southern Europe (Scarabaeinae, Aphodiinae, Geotrupinae). Biological Conservation 141:2879-2887.

Kleijn, D., and W. J. Sutherland. 2003. How effective are European agrienvironment schemes in conserving and promoting biodiversity? Journal of Applied Ecology 40:947-969.

Lee, S. M., and A. Chao. 1994. Estimating population size via sample coverage for closed capture-recapture models. Biometrics 50:88-97.

Loвo, J. M. 1993. Estimation of dung beetle biomass (Coleoptera: Scarabaeoidea). European Journal of Entomology 90:235-238.

Loвo, J. M. 2001. Decline of roller dung beetle (Scarabaeinae) populations in the Iberian Peninsula during the 20th century. Biological Conservation 97:43-50.

LoBo, J. M., AND A. L. V. Davis. 1999. An intercontinental comparison of dung beetle diversity between two Mediterranean-climatic regions: local versus regional and historical influences. Diversity and Distributions 5:91-103.

Lobo, J. M., J. Hortal, and F. J. Cabrero-Sañudo. 2006. Regional and local influence of grazing activity on the diversity of a semi-arid dung beetle community. Diversity and Distributions 12:111-123.

Lumaret, J. P., AND F. Errouissi. 2002. Use of anthelmintics in herbivores and evaluation of risks for the nontarget fauna of pastures. Veterinary Research 33:547-562.

Lumaret, J. P., E. Galante, C. Lumbreras, J. Mena, J. L. Bernal, J. F. Cooper, N. Kadiri, M. Bertrand, and D. Crowe. 1993. Field effects of antiparasitic drug Ivermectin residues on dung beetles (Insecta, Coleoptera). Journal of Applied Ecology 30:428-436.

Lumaret, J. P., N. Kadiri, and M. Bertrand. 1992. Changes in resourcesconsequences for the dynamics of dung beetle communities. Journal of Applied Ecology 29:349-356.
Lumaret, J. P., And A. Kirk. 1991. South temperate dung beetles. In: I. Hanski and Y. Cambefort [EDS.]. Dung beetle ecology. Princeton, NJ, USA: Princeton University Press. p. 97-115.

Lumaret, J. P., and M. I. Martínez. 2005. El impacto de productos veterinarios sobre insectos coprófagos: consecuencias sobre la degradación del estiércol en pastizales. Acta Zoológica Mexicana (n.s.) 21:137-148.

MagurRan, A. E. 2004. Measuring biological diversity. Oxford, UK: Blackwell Science. $256 \mathrm{p}$.

Navarrete, D., and G. Halffter. 2008. Dung beetle (Coleoptera: Scarabaeidae: Scarabaeinae) diversity in continuous forest, forest fragments and cattle pastures in a landscape of Chiapas, Mexico: the effects of anthropogenic changes. Biodiversity and Conservation 17:2869-2898.

NAVEH, Z., AND R. H. WhitTAKER. 1979. Structural and floristic diversity of shrublands and woodlands in northern Israel and other Mediterranean areas. Vegetatio 41:171-190.

Nichols, E., T. Larsen, S. Spector, A. L. Davis, F. Escobar, M. Favila, and K. Vulinec. 2007. Global dung beetle response to tropical forest modification and fragmentation: a quantitative literature review and meta-analysis. Biological Conservation 137:1-19.

Numa, C. 2008. Análisis multiescalar de la diversidad de escarabajos coprófagos (Coleoptera Scarabaeoidea) en la península Ibérica [PhD thesis]. Alicante, Spain: CIBI0-Univesidad de Alicante. $173 \mathrm{p}$.

Numa, C., J. R. Verdú, A. Sánchez, and E. Galante. 2009. Effect of landscape structure on the spatial distribution of Mediterranean dung beetle diversity. Diversity and Distributions 15:489-501.

Piasentier, E., E. Saccà, and S. Bovolenta. 2007. Dietary selection and ingestive behaviour of fallow deer and sheep grazing on adjacent monocultures of white clover and tall fescue. Small Ruminant Research 71:222-233.

SowIG, P. 1995. Habitat selection and offspring survival rate in three paracoprid dung beetles: the influence of soil type and soil moisture. Ecography 18:147-154.

StatsDirect. 2008. StatsDirect Statistical Software. Version 2.7.2. Cheshire, UK: StatsDirect Ltd.

Svenning, J.-C. 2002. A review of natural vegetation openness in north-western Europe. Biological Conservation 104:133-148.

Trotter, C. G., A. M. Nicol, and M. J. Ridgway. 2006. Sheep and deer grazing of pasture close to cattle dung pats. Proceedings of the New Zealand Society of Animal Production 66:59-63.

Vaquero de la Cruz, J. 1997. Flora vascular y vegetación. In: V. García [ed.]. Parque Nacional de Cabañeros. Madrid, Spain: Editorial Ecohabitat. p. 95-154.

Verdú, J. R. 1998. Biología de los escarabeidos coprófagos en ecosistemas iberolevantinos. Ecología y análisis biogeográfico (Coleoptera, Scarabaeoidea) [PhD thesis]. Alicante, Spain: University of Alicante. 393 p.

Verdú, J. R., M. B. Crespo, and E. Galante. 2000. Conservation strategy of a nature reserve in Mediterranean ecosystems: the effects of protection from grazing on biodiversity. Biodiversity and Conservation 9:1707-1721.

Verdú, J. R., and E. Galante. 2004. Behavioural and morphological adaptations for a low-quality resource in semi-arid environments: dung beetles (Coleoptera, Scarabaeoidea) associated with the European rabbit (Oryctolagus cuniculus L.). Journal of Natural History 38:705-715.

Verdú, J. R., C. E. Moreno, G. Sanchez-Rojas, C. Numa, E. Galante, and G. Halffter. 2007. Grazing promotes dung beetle diversity in the xeric landscape of a Mexican Biosphere Reserve. Biological Conservation 140:308-317.

VeRDÚ, J. R., AND J. M. LOBO. 2008. Ecophysiology of thermoregulation in endothermic dung beetles: ecological and geographical implications. In: S. Fattorini [ED.]. Insect ecology and conservation. Kerala, India: Research Signpost. p. 1-28.

Villar, L., and P. Montserrat. 1995. Función del pasto en los espacios naturales protegidos y su entorno. In: Actas de la XXXV Reunión Científica de la S.E.E.P.; 21-26 May 1995; Centro de Investigación y Tecnología Agrarias, Universidad de la Laguna. Tenerife, Spain. p. 9-12.

Wardhaugh, K. G., B. C. Longstaff, and R. Morton. 2001. A comparison of the development and survival of the dung beetle, Onthophagus taurus (Schreb.) when fed on the faeces of cattle treated with pour-on formulations of eprinomectin or moxidectin. Veterinary Parasitology 99:155-168.

Young, S. G., And A. W. Bowman. 1995. Nonparametric analysis of covariance. Biometrics 51:920-931. 